\title{
Cisgenesis and Intragenesis: New tools For Improving Crops
}

\author{
Espinoza C, Schlechter R, Herrera D, Torres E, Serrano A, Medina C, Arce-Johnson P. \\ Departamento de Genética Molecular y Microbiología. Facultad de Ciencias Biológicas. Pontificia Universidad Católica de Chile. Santiago, Chile.
}

\begin{abstract}
Genetically Modified Organisms (GMO) could be the answer for many relevant problems affecting crops. However, improving crops through GMO is also often associated with safety concerns, environmental risks and health issues due to the presence of foreign DNA. These limitations have prompted the development of alternative technologies. Recently, cisgenesis and intragenesis have been developed as new tools aimed to modify crops. While cisgenesis involves genetic modification using a complete copy of natural genes with their regulatory elements that belong exclusively to sexually compatible plants, intragenesis refers to the transference of new combinations of genes and regulatory sequences belonging to that particular species. So far, application of cisgenesis and intragenesis as alternatives to conventional transgenesis are limited to a few species, mainly due to the lack of knowledge of the regulatory sequences required. The grape is one of the most cultivated crops worldwide and is the most economically relevant crop in Chile. Its genomic sequence has been completed, making available new sources of information to improve grape traits by genetic manipulation. This review is focused on the current alternatives to transgenesis in plants, including new approaches to develop marker-free crops, their application to economically relevant crops and future perspectives in the area. Also, the identification of grapevine promoters with a wide range of expression profiles is shown. The expression pattern of these genes was analyzed in different tissues and developmental stages, as well as under several stresses and stimuli, giving a broad range of expression patterns, including genes expressed exclusively during ripening, in response to sugars, senescence and biotic stress, among others. Genes with strong and constitutive expression were also identified. Functional analysis using reporter genes has been conducted in order to confirm the promoter's transcription activity, opening new possibilities for developing cisgenic/intragenic grapevines.
\end{abstract}

Key words: cisgenesis, intragenesis, grapevine promoters, VvGRIP24.

\section{INTRODUCTION}

Plant biotechnology refers to the development of technologies based on biological systems to improve agricultural practices. The hallmark of green biotechnology is the genetic modification of crops in order to confer new traits, by either the expression of a foreign gene or the suppression of an endogenous protein to modify a function. Such organisms are known as Genetically Modified Organisms (GMO). In 2012, the global area of biotech crops was 170 million hectares, including 28 countries that adopted this technology since 1994 (Clive, 2012). Genetically modified crops include herbicide-tolerant and pest-resistant plants developed to improve crop yields and to reduce environmental impacts. For example, the adoption of Bt transgenic cotton, a pest-resistant modified crop, resulted in a $24 \%$ increase in crop yield per acre and a $50 \%$ increase in profit among smallholders over six years (2002-2008) in India (Kathage and Qaim, 2012). In China, a reduction in pesticide usage, exposure and poisoning has been observed since the adoption of Bt cotton (Pray et al., 2002). Globally, the adoption of GMOs since 1996 is associated with an $18.3 \%$ reduction in the environmental impact in cultivated areas and a reduction of $8.9 \%$ in pesticide and herbicide usage (Brookes and Barfoot, 2013).

The first genetically engineered crop commercialized was the Flavr Savr ${ }^{\mathrm{TM}}$ tomato in 1994. These tomatoes had a longer shelf life through the expression of an antisense RNA to regulate the level of a polygalacturonase enzyme involved in fruit ripening (Kramer and Redenbaugh, 1994). Nowadays, transgenic crops include different traits, such as conferring tolerance against pesticides, herbicides, biotic and abiotic stresses and the production of proteins to modify metabolic pathways and/or to gain a new function to add nutritional value. For example, the Bt transgenic crops contain the CRY1AA, CRY1AB and/or CRY1AC genes to encode a $\delta$-endotoxin from Bacillus thuringiensis for pest control (Estruch et al., 1997; Roh et al., 2007). In soybean, canola, cotton and maize, herbicide-resistant transgenic lines were introduced in 1996 to simplify weed-control practices. The glyphosatetolerant crops carry in their genome a gene derived from a strain of Agrobacterium tumefaciens encoding the enzyme 5-enolpyruvylshikimate-3-phosphate (EPSP) synthase, which is insensitive to the inhibitory effect of glyphosate (Owen and Zelaya, 2005; Funke et al., 2006). In rice, a carotenoidaccumulating variety (Golden Rice) was generated by the manipulation of the provitamin A biosynthetic pathway, helping to treat vitamin A deficiencies (Beyer et al., 2002). Also, transgenic approaches are being taken to handle drought, mineral deficient-soils and soil salinity. Expression of vacuolar transporters such as NHX1, SOS1 and AVP1 are examples of generating salt tolerance in plants by sequestration of ions into the vacuole (Yamaguchi and Blumwald, 2005).

Although transgenic crops are a promising tool for agriculture and have shown to improve economic development, they have been a major concern for public opinion since their introduction in the 1990s. Public acceptance is an important factor for the successful development of a technology, and both ethical concerns and risk perceptions have emerged about biotech crops, mainly due to most of the approved GMOs containing genetic elements derived from non-compatible species and containing selectable markers for antibiotics or herbicide resistance (Purchase, 2005). In addition, there are several limitations for the production and 
commercialization processes of genetically modified crops. For example, the total cost of the development and authorization of a new transgenic crop is estimated to be around US\$ 135 million (Clive, 2012), concentrating the establishment of this technology exclusively in multinational corporations. The regulation of these crops is based on the methods used to insert genetic material instead of an assessment on the potential risk of the modified traits (Bradford et al., 2005). Moreover, most of the risk assessments deal with the potential ecological and human health effects upon the release of a GMO to alleviate the arising concerns of the public about the impact on biodiversity and the expression of potential allergens in GMOs (Singh et al., 2006). These constraints clearly establish market barriers to the commercialization of GMOs worldwide.

\section{CISGENESIS AND INTRAGENESIS}

Considering public concerns about safety issues regarding transgenic crops, cisgenesis and intragenesis have been developed as new tools in crop modification and plant breeding (Figure 1). The term "cisgenic plant" was first introduced a few years ago and it refers to "a crop plant that has been genetically modified with one or more genes (containing introns and flanking regions such as native promoter and terminator regions in a sense orientation) isolated from a crossable donor plant" (Schouten et al., 2006b). Basically, it implies that the genetically modified cisgenic crop contains genes maintaining their natural genetic composition, i.e. a perfect complete copy a natural gene with all its regulatory elements. The source of a cisgene is the same plant species or a sexually compatible species as used for traditional breeding. However, unlike traditional breeding, cisgenic crops contain exclusively the gene or genes of interest and no undesired genetic elements.

On the other hand, intragenesis refers to GMOs where the introduced intragene also originates from the same species or a crossable species, but in contrast to cisgenes, intragenes are hybrid genes, which can have genetic elements from different genes and loci (Rommens et al., 2007). As a result, the expression of a certain gene can be modified with the use of different promoter or terminator regions. Intragenesis allows the construction of new genetic combinations, introducing variability for gene expression, the creation of novel expression patterns and consequently new GMOs with innovative properties. Based on the use of native genes in comparison with the use of hybrid genes, cisgenesis can
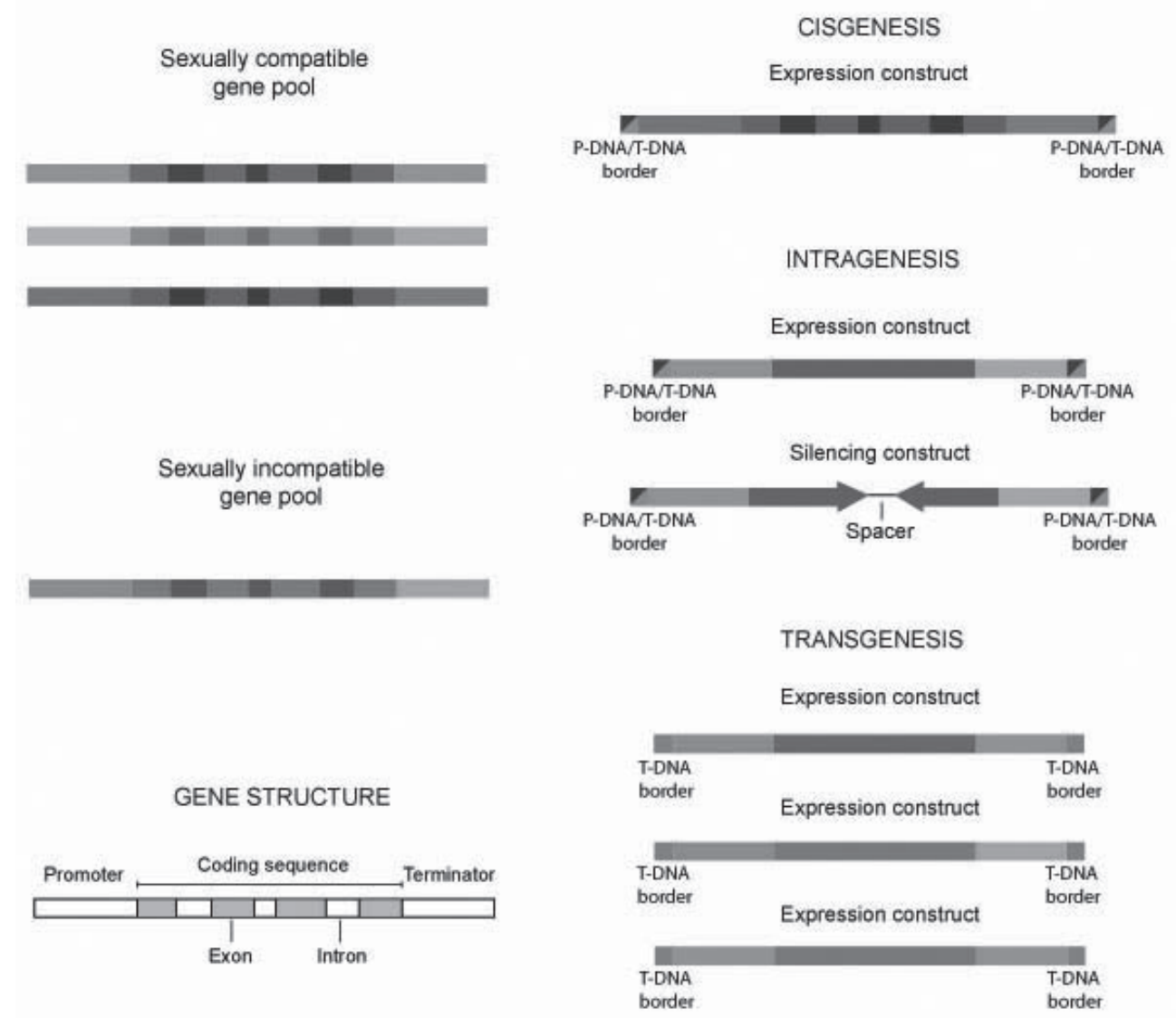

Figure 1. Schematic representation of different strategies used for genetic modification according to definitions of cisgenesis, intragenesis and transgenesis. In cisgenesis, expression constructs must contain complete genetic elements from a sexually compatible gene pool (promoter, coding sequence including introns and terminator). In intragenesis, expression or silencing constructs can contain genetic elements from different genes within a sexually compatible gene pool. In transgenesis, expression constructs with genetic elements derived from both sexually compatible and incompatible gene pools are designed. When an Agrobacterium-mediated transformation method is used, P-DNA or T-DNA borders can be inserted into the plant genome to generate cisgenic or intragenic approaches; while for transgenic approaches, T-DNA borders are commonly inserted. Adapted from Holme et al. (2006). 
be considered much closer to traditional breeding than intragenesis. RNA interference (RNAi) approaches using native DNA sequences are also considered as intragenesis.

Another key difference between cisgenesis and intragenesis, is regarding the T-DNA borders or other sequences finally transferred to the plant as a consequence of the Agrobacteriummediated transformation process, a topic which is not exempt from a certain degree of controversy (Holme et al., 2013). While some authors agree in the fact that intragenic and cisgenic plants should be generated using border sequences originating from the crossable gene pool, others have proposed that the source of border sequences is not a limiting factor; opening the possibility to use canonical T-DNA borders similar to any GMO. Plant-derived sequences with similar properties to T-DNA, also known as plant transfer DNAs or P-DNAs, have been identified in several plant species (Rommens et al., 2005). Arguments favoring the use of T-DNA claim that those sequences can be found within plant genomes, and since they are by nature non-coding sequences, they should be safe to use (Schouten et al., 2006a). In this regard, P-DNAs used to replace T-DNA sequences are essentially identical to T-DNA (Rommens et al., 2004; Schouten et al., 2006a).

Cisgenic and intragenic plants should also be free from other non-plant sequences, such as vector backbone and selection markers. Several strategies to either avoid or remove marker genes have been described, mainly based on the target plant and the efficiency of the transformation method used. For instance, when the transformation efficiency is high, the use of selection markers can be avoided. Then transformed lines are selected by the presence of the specific gene sequence introduced, but this requires the analysis of numerous plants and is both expensive and time consuming. To overcome this, marker deletion methods based on sitespecific recombination have been developed. In those cases, marker selection genes are flanked with specific recombination sites (R/Rs system), and later, when transformed plants have been selected, the recombination activity is induced with the consequent release of the marker gene. Marker excision can be further confirmed by molecular biology techniques. Cisgenic and intragenic apples (Joshi et al., 2011; Vanblaere et al., 2011) as well as intragenic strawberries (Schaart et al., 2004) have been obtained using this marker-free technology. Co-transformation is another alternative to produce markerfree plants. This method is based on the integration of the marker gene and the transgene of interest in different positions of the plant's genome, allowing the segregation of both genes in different progeny. Co-transformation can be done using two transformation vectors, one including the gene of interest and one with the marker gene. Such an approach has been successfully used to generate cisgenic barley plants (Holme et al., 2012) and durum wheat (Gadaleta et al., 2008).

The scientific community has interest in promoting less stringent regulations for cisgenic/intragenic crops. For instance, the European Commission (EC) requested the European Food Safety Authority (EFSA) to determine the hazards of cisgenic/ intragenic crops compared to transgenesis or traditional breeding (EFSA Panel on Genetically Modified Organisms, 2012). This report states that hazards associated with cisgenesis, intragenesis, transgenesis and conventional breeding originate from the source of the gene, the phenotype and possible genome rearrangements as a result of the modification. Moreover, it was proposed that cisgenesis could imply similar hazards to traditional breeding, while transgenesis and intragenesis are less predictable. In the USA a similar situation occurs; the Environmental Protection Agency (EPA) is discussing the regulatory framework for these crops (Holme et al., 2013). Cisgenic and intragenic crops were intended to facilitate the approval of the stringent regulations of transgenic cultures, but unfortunately the current situation places both technologies in the same category as transgenic crops.

\section{APPLICATION OF CISGENESIS AND INTRAGENESIS TO IM- PROVE TRAITS IN RELEVANT CROPS}

Several traits have been incorporated to relevant crops by cisgenic or intragenic approaches. These species include potato (de Vetten et al., 2003; Rommens et al., 2004; Rommens et al., 2006; Rommens et al., 2008; Haverkort et al., 2009; Chawla et al., 2012), apple (Joshi et al., 2011; Vanblaere et al., 2011), strawberry (Schaart et al., 2004), alfalfa (Weeks et al., 2008), perennial ryegrass (Bajaj et al., 2008), poplar (Han et al., 2011), barley (Holme et al., 2012) and durum wheat (Gadaleta et al., 2008). Some examples reported in the literature are described below.

The first intragenic potato was developed to produce high amylopectin content (de Vetten et al., 2003). This approach was based on the silencing of the granule-bound starch synthase gene (GBSS), which is responsible for the synthesis of amylose in potato. The starch composition in potato is an important trait, and currently it is difficult to obtain the cultivated tetraploid potatoes with the desired content of amylose and amylopectin. Thus, strategies to silence either amylose or amylopectin synthetic genes open the possibility of obtaining tetraploid cultivars that contain all the desired traits present in the original cultivar (Holme et al., 2013). This potato was released to the field in the EU in 2007 (B/NL/07/04) by the company AVEBE and contains T-DNA borders and a GBSS terminator from potato or a nopaline synthase gene terminator from Agrobacterium tumefaciens for regulation of gene expression. Therefore, the question arises whether it can be considered as fully intragenic. Other intragenic approaches have addressed potato processing qualities. For instance, enzymatic browning was diminished by the silencing of a polyphenol oxidase gene ( $P P O)$, which catalyzes the oxidation of cytoplasmatic polyphenols causing the precipitation of black melanin and compromising tuber quality during storage (Rommens et al., 2004). Another important potato trait is cold-induced sweetening, which is caused by high starch degradation triggered by low temperature during storage. To prevent this, intragenic potatoes silenced in two genes involved in starch degradation, water dikinase (R1) and amyloplast-targeted phosphorylase-L $(P h L)$ were constructed (Kawchuk et al., 1999). Subsequently, the PPO, R1 and PhL genes were all silenced in potato, producing tubers with remarkable properties (Rommens et al., 2006). Induction of tolerance to the most important potato disease, late blight caused by the oomycete Phytophthora infestans, is one of the main challenges in potato research. Resistance genes ( $R$-genes) present in wild potatoes have been transferred into potato varieties by traditional breeding, but this is limited due to the differences in the ploidy levels between potato species (Haverkort et al., 2009; Park et al., 2009). For this reason, the Durable Resistance against Phytophthora (DuRPh) program intends to introduce several $R$-genes from wild potatoes, with 
their native regulatory sequences, into cultivated potatoes (Holme et al., 2013). This cisgenic approach also took into account the use of marker-free technologies (de Vetten et al., 2003; Haverkort et al., 2009).

In the case of fruit trees, the most important apple disease is scab, which is caused by the ascomycete Venturia inaequalis. All cultivated apples are susceptible to this pathogen, and recently the HcrVf2 gene present in the scab resistance locus $V f$ was introduced in apple cv. Gala (Vanblaere et al., 2011). The transferred gene contains its own regulatory sequences, i.e. promoter and terminator and in fact, this study claims to be the first report of the generation of a "true cisgenic plant" (Vanblaere et al., 2011). An intragenic approach also aimed to induce scab resistance used the same HcrVf2 gene (Joshi et al., 2011), but in this case, the resistance gene is controlled by the promoter and terminator of the small subunit of the apple rubisco gene. However, scab resistance in apples has not yet been shown.

Modification of tree architecture and growth rates is a major concern for the woody plant industry. Based on this, a cisgenic approach developed in poplar seeks to address both issues (Han et al., 2011). For this, genes coding for gibberellic acid biosynthesis enzymes together with their native regulatory sequences were overexpressed in poplar trees, leading to an increase in tree growth rate. In agreement with this, overexpression of catabolic genes as well as negative regulators results in reduced growth and tree size. Therefore, cisgenic or intragenic strategies could be useful for plants with long lifetimes and high heterozygosity levels, in which traditional breeding is very limited.

Cisgenic barley was developed by the introduction of several copies of the native phytase gene (Holme et al., 2012). Phytase catalyzes phosphate release from phytic acid, making phosphate available to be absorbed by animals. This strategy has been shown to be promising in increasing phosphate bioavailability, and therefore could represent an alternative to avoid the addition of microbially-derived phytase to feed, and to reduce the current environmental pollution derived from phosphate.

\section{CISGENESIS AND INTRAGENESIS IN GRAPES}

So far, application of cisgenesis and intragenesis as alternatives to conventional transgenesis is limited to a few species, mainly due to the lack of knowledge of the regulatory sequences required. For several relevant crops, the current knowledge of full genomic sequences has opened up new possibilities to use genes and their native regulatory sequences to improve important traits. For instance, the grape is one of the most important crops worldwide, with a significant economic impact for many countries; to date, no cisgenic or intragenic grapevine plants have been described. Species such as grapes are especially sensitive to transgenesis due to the concerns of vintners about the introduction of foreign genes into elite grape varieties and their potential effects on enological characteristics and wine attributes. Thus knowledge about native genes suitable for genetic manipulation will help to improve grape characteristics by transgenic technologies. In this scenario identification of promoters is crucial, but it is even more important to characterize their expression patterns. For this reason, we have studied a wide range of grape promoters and also conducted functional analyses. These approaches have allowed us to identify regulatory sequences with a broad range of expression patterns, including genes expressed exclusively during ripening, in response to sugars, senescence and biotic stress, among others; as well as genes with strong and constitutive expression. Some examples of these promoters are discussed below.

In Vitis vinifera, berry development and ripening occur together with an important accumulation of sugars in mesocarp cells, mainly from veraison onwards, a state that defines the beginning of ripening (Deluc et al., 2007). Synthesis and accumulation of anthocyanin, phenolic compounds and aroma precursors also occur during ripening, processes that are strongly correlated with sugar accumulation (Figure 2) (Agasse et al., 2009). It has been shown that glucose and fructose present in berries induce anthocyanin biosynthesis, in both cell cultures as well as fruit discs (Larronde et al., 1998; Zheng et al., 2009). This induction is mediated by transcription factors that regulate the expression of structural genes of the anthocyanin pathway. Among them VvMYBA1, which belongs to the R2R3MYB family, is essential for anthocyanin synthesis through the regulation of the gene coding for UDP-glucose 3-O-flavonoid:glycosyltransferase (UFGT) (Kobayashi et al., 2002; Walker et al., 2006; Walker et al., 2007; Cutanada et al., 2009). VvMYBA1 transcript levels were analyzed through berry development (Figure 2B) and it was observed that $V v M Y B A 1$ is expressed from veraison to ripening, in parallel with the increase of soluble sugars. On the other hand, sugar transporters are essential to facilitate sugar movement to the cell where these molecules, mainly as monosaccharides, accumulate in the vacuole (Williams et al., 2000; Agasse et al., 2009). In grapes, six putative monosaccharide transporters have been cloned, named VvHT1-6 (Fillion et al., 1999; Vignault et al., 2005; Hayes et al., 2007). Most of them are localized in the cell membrane. However, less is known about monosaccharide transporters located in the vacuole membrane or tonoplast. We have characterized the VvHT6 gene. The predicted protein has a central loop, which is characteristic of the Tonoplast Transporter proteins in Arabidopsis (Wormit et al., 2006). Therefore, VvHT6 was named as VvTMT2 (Vitis vinifera Tonoplast Monosaccharide Transporter 2). VvTMT2 expression during berry ripening reaches a maximum level at veraison, with a decrease at the ripening stage (Figure 2C). This expression pattern correlates with the increase in berry sugar content. In silico analyses of VvMYBA1 and VvTMT2 promoters using the GRAPE-Hunt program (unpublished), reveal the presence of cis elements that are related to sugar regulation, suggesting the expression of both genes might be controlled by sugars (Figure $2 \mathrm{~B}$ and $2 \mathrm{C}$ ). Both $V v M Y B A 1$ and $V v T M T 2$ constitute examples of genes expressed during grape ripening. This kind of regulation opens the opportunity to use these promoters to express genes at specific stages during berry development, reducing the risk of altering other aspects of berry maturity. Moreover, pathogen resistance could also be specifically induced at certain berry ripening stages. Commercial grape cultivars are highly susceptible to a variety of pathogens. For instance, fungal diseases cause severe yield losses in economically important varieties worldwide. Powdery mildew (Erysiphe necator) (Gadoury et al., 2012), downy mildew (Plasmopara viticola) (Gessler et al., 2011) and grey mold (Botrytis cinerea) (Dean et al., 2012) are the most prevalent diseases that cause major crop losses around the world. These pathogens can seriously infect grapes either during maturity or post-harvest life. Hence, triggering the 
synthesis of antifungal compounds at specific stages could provide more efficient pathogen resistance strategies without detrimental effects on fruit quality.

For other biotechnological approaches, strong and constitutive endogenous promoters are needed. Searching for other alternatives to drive gene expression in a constitutive manner and based on previous transcript profiling data (Espinoza et al., 2007; Vega et al., 2011), we have identified a grape gene with remarkable characteristics. The gene VvGRIP24 showed high expression level in grape leaves and berries infected with virus (Grapevine Leafroll Virus-3), but also in healthy or non-infected tissues. Therefore, under the evaluated conditions VvGRIP24 is strongly expressed, independent of the treatment applied. This gene has been previously described as a Grape Ripening-Inducer and it was shown to be highly expressed in old leaves and in early stages of berry development (Davies and Robinson, 2000) VvGRIP24 belongs to the metallothionein-like protein family, present in mammals, cyanobacteria, yeast, nematodes and higher plants (Robinson et al., 1993). Metallothionein proteins are low molecular weight proteins, characterized by high cysteine residue contents; they play an important role in metal homeostasis and detoxification (Robinson et al., 1993; Liu et al., 2002). The classification of metallothionein proteins is based on the position of the cysteine residues and all plant metallothioneins belong to Class II, which is further divided into four types considering the arrangement of these residues (Xue et al., 2009). VvGRIP24 encodes a 63-amino acid protein belonging to type three (Davies and Robinson, 2000; Xue et al., 2009). In order to characterize this gene and its promoter we performed a VvGRIP24 expression analysis in different tissues of the red cultivar Cabernet Sauvignon by Real Time PCR (Figure 3). VvGRIP24 is strongly expressed in all evaluated tissues (leaf, pulp, seed, root, berry and flower). Interestingly, $V v G R I P 24$ expression was higher than $V v G 3 P D H$, a widely known grapevine housekeeping gene, in most of the studied tissues. This shows the potential use of the VvGRIP24 promoter as an endogenous constitutive promoter

\section{A}

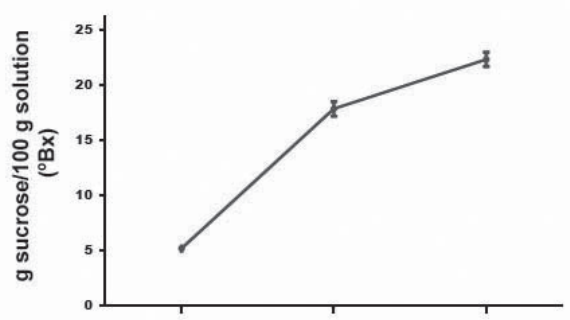

B

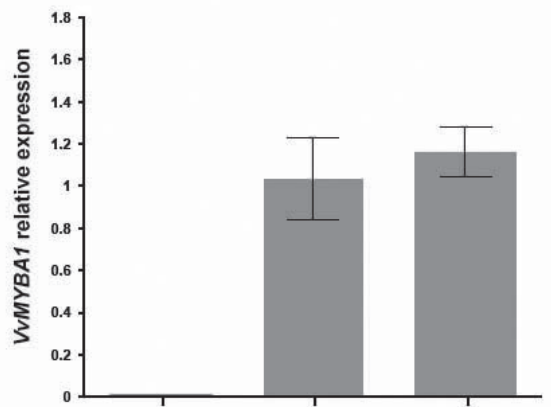

$2 \mathrm{~Kb}$ VvMYBA1 promoter

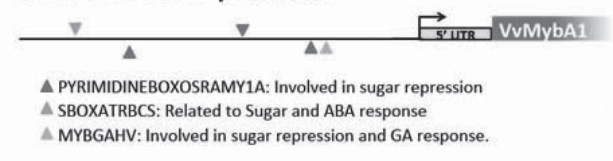

C

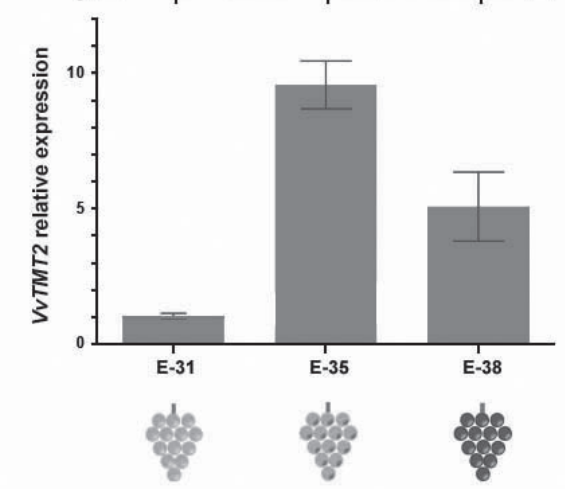

$2 \mathrm{~Kb}$ VVTMT2 promoter

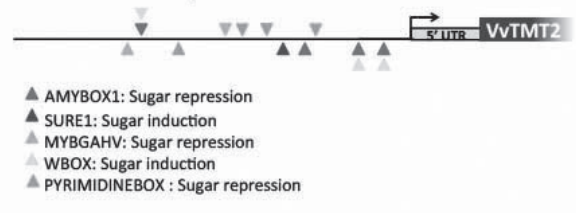

Figure 2. Stage-specific gene expression during grape (Vitis vinifera) berry development. (A) Measurement of soluble sugars ( ${ }^{\circ}$ Brix) in berry mesocarp at three developmental stages. Relative expression of $V v M Y B A 1$ (B) and VvTMT2 (C) at three berry developmental stages, including an in silico prediction of putative motifs in the promoter region (2 kb length) of each gene. For RT-qPCR measurements, VVG3PDH was used as the housekeeping gene. Berry ripening stages E-31 (setting), E-35 (veraison) and E-38 (harvest) were defined according to Coombe et al. (1995). For in silico promoter analyses, the GRAPE-Hunt (Genetic Regulation Analysis by Promoter Elements Hunting) software was used (unpublished). For this, a $2 \mathrm{~kb}$ region upstream of the corresponding start codon was searched for transcription factor binding sites (TFBSs) obtained from the PLACE database (http://www.dna.affrc.go.jp/PLACE/). GRAPEHunt calculates a Poisson $p$-value by comparing observed and expected values, which can be estimated by the presence of those TFBSs in a $10 \mathrm{~kb}$ randomly-generated sequence based on the grapevine genome composition. 
in grapevine. To study the $V v G R I P 24$ promoter we performed an in silico analysis of the cis regulatory elements present 2 $\mathrm{kb}$ region upstream of the start codon, using the GRAPEHunt program (unpublished). Significantly overrepresented elements are interestingly grouped from -1 to $-1000 \mathrm{bp}$ as shown in Figure 4. Several cis elements that respond to different stimuli and conditions are present in this region of the VvGRIP24 promoter. Tissue-specific expression elements represent about $31 \%$ of the total number of significant motifs present in the VvGRIP24 promoter, while metal responsive elements correspond to $19 \%$ of total motifs. Metal responsive motifs include CURECORECR, related to the copper response (Quinn et al., 2000) and the SURECOREATSULTR11 element, which is associated with the sulfur response element SURE (Maruyama-Nakashita et al., 2005). Using public transcript profiling databases to analyze the expression of $V v G R I P 24$, we found that this gene is strongly expressed in several abiotic stresses such as osmotic stress, salt stress and low temperature,

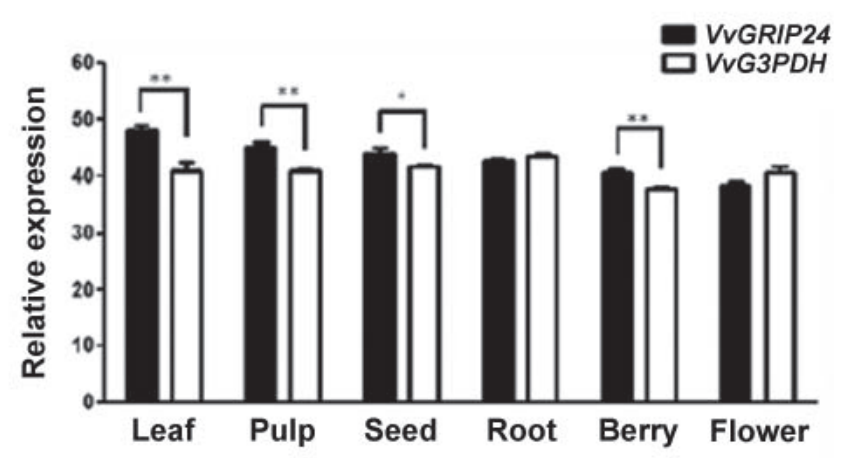

Figure 3. Gene expression analysis of VvGRIP24 in Vitis vinifera cv. Cabernet Sauvignon. RT-qPCR experiments for gene expression analysis of $V_{V} G R I P 24$ and $V v G 3 P D H$ were performed in different tissues of grape plants. Leaf, pulp, seed, root, berry and flower tissues were used for the analysis. Gene expression was normalized against $V v U B I-L 40$. Significance level: ${ }^{* *} p<0.001$ and ${ }^{*} \mathrm{p}<0.05$.
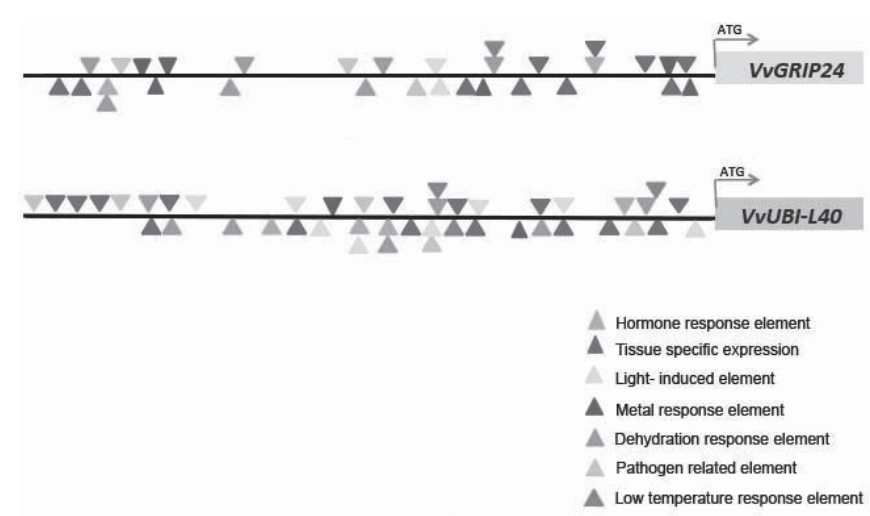

Figure 4. In silico analysis of the cis elements present in VvGRIP24 and VvUBI-L40 promoter sequences. Analysis of the promoter sequence (1 kb length) of $V_{v} G R I P 24$ (A) and $V_{v} U B I-L 40$ (B) using the GRAPE-Hunt program to determine the different motifs present. Motifs are grouped by color according to tissue specificity and stresses. as well as during berry development (VV1 and VV5 experiments; www.plexdb.org). Similarly to the VvGRIP24 gene, metallothionein GhMT3a from cotton (Gossypium hirsutum) is up-regulated by several conditions such as high salinity, drought, low temperature, stress induced by heavy metals, abscisic acid, ethylene and also reactive oxygen species (ROS) (Xue et al., 2009). The wide range of VvGRIP24 responses could be explained by the presence of numerous and diverse cis regulatory elements in its promoter region (Figure 4). To characterize the VvGRIP24 promoter activity, the 1000 bp upstream sequence was cloned upstream of the reporter gene uidA and used to transform the model plant Arabidopsis thaliana. VvGRIP24 promoter activity through GUS. Staining was observed in cotyledons, leaves, roots and flowers, and this pattern was maintained in adult leaves mainly associated with vascular tissues; no GUS staining was detected in seeds (Figure 5). We also performed a transient expression of the $V v G R I P 24$ promoter with the reporter GUS by agroinfiltration in grape tissues (Figure 6). GUS staining was detected in embryogenic tissues of 110 Richter rootstock, in Cabernet Sauvignon roots and leaves and in Thompson Seedless berry discs. These results strongly suggest that $1000 \mathrm{bp}$ of VvGRIP24 promoter is sufficient to drive reporter gene expression in a wide range of tissues.

Ubiquitin is a small (76 amino acid) protein found in all eukaryotes. It is also highly conserved, with only three amino acid variations described among sequences from higher plant and animal species (Callis et al., 1990). Ubiquitin is expressed in the form of different precursors; one of these is a linear fusion protein consisting of five or more ubiquitin copies (polyubiquitin), and it is also produced as an N-terminal fusion to the ribosomal proteins S27a and L40, where it acts as a chaperone assisting the formation of the holoribosome (Catic et al., 2007). Ubiquitin gene promoters have been isolated from a variety of plants and tested for their ability to drive gene expression in tomato (Hoffman et al., 1991), Arabidopsis (Norris et al., 1993), rice (Lu et al., 2008), switchgrass (Mann et al., 2011) and potato (Carbarino et al., 1995). Little is known about the ubiquitin promoter in grapes. Recently, the transcription activity of 31 gene promoters from various grape genotypes was reported (Li et al., 2012). Those promoters greatly differ in their activity, and additionally showed variations in the expression pattern of the reporter genes. Here we characterized the VvUBI-L40 promoter, a gene widely used as reference for normalization of gene expression by RT-qPCR (Reid et al., 2006). Similarly to the VvGRIP24 promoter, a region of $1000 \mathrm{bp}$ upstream of the VvUBI-L40 start codon showed a high density of motifs associated with a wide range of responses such as light, hormones, tissue specific expression and abiotic stress, among others (Figure 4). The expression pattern of the $V v U b i-L 40$ promoter was evaluated through beta-glucuronidase (GUS) activity in different tissues and developmental stages in transgenic Arabidopsis thaliana plants (Figure 5). The VvUbi-L40 promoter is able to drive relatively high levels of GUS reporter expression in cotyledons, roots, siliques and young leaves. In adult leaves we observed a decrease in GUS staining in comparison to young leaves, and this phenotype was more evident in older leaves. No GUS staining was detected in flowers. Analysis of transient activity of the $V v U b i-L 40$ promoter with the uidA reporter in grapes showed very limited GUS staining, which was only evident in embryogenic tissues and roots (Figure 6). 


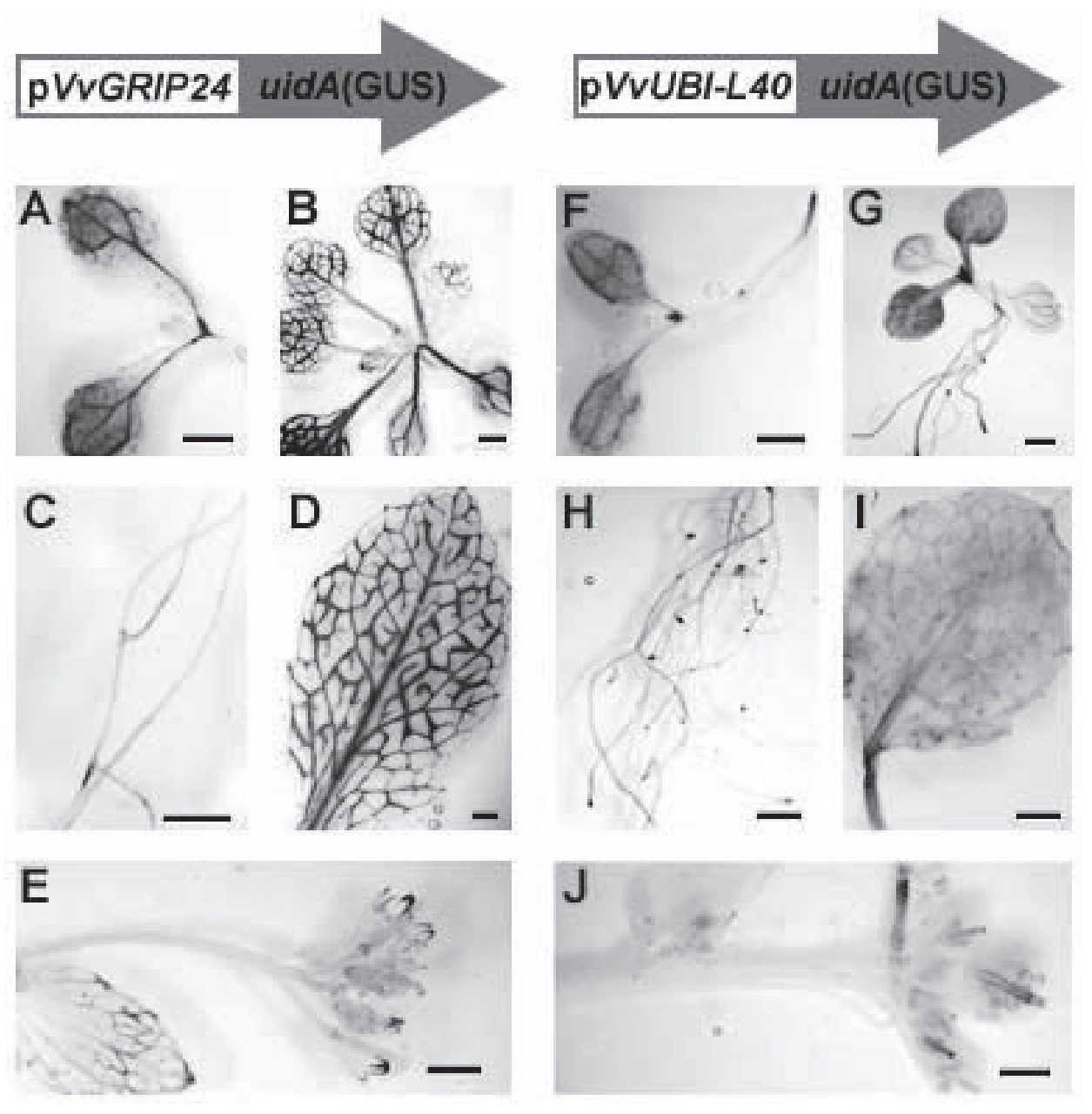

Figure 5. Histochemical localization of $\beta$-glucuronidase (GUS) activity in transgenic lines of Arabidopsis thaliana plants transformed with VvGRIP24::GUS or VvUBI-

L40::GUS. A GUS activity assay was performed in transgenic plants expressing VvGRIP24::GUS (A-E) or VvUBI-L40::GUS (F-J) at different developmental stages and tissues. Assays were performed in cotyledons $(A, F)$, rosette leaves $(B, G)$, roots $(C$, $H)$, mature leaves $(D, I)$ and flowers $(\mathrm{E}, \mathrm{F})$. Images are representative of three VvUBI-L40::GUS and two VvGRIP24::GUS transgenic Arabidopsis lines, which were generated using the pKGWFS7 vector (Karimi et al., 2002). $\mathrm{Bar}=1 \mathrm{~mm}$

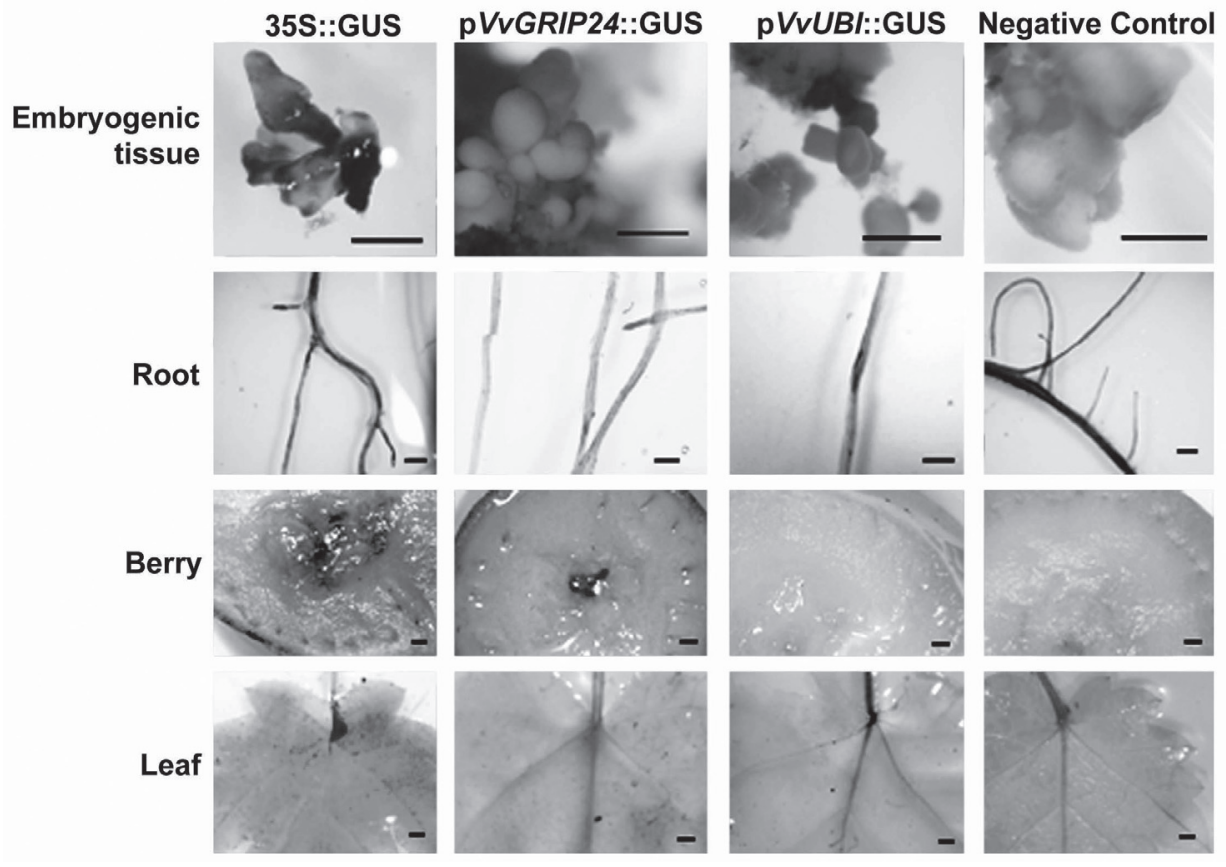

Figure 6. Histochemical localization of $\beta$-glucuronidase (GUS) activity of pVvUBI-L40::GUS and PVvGRIP24::GUS in different grape tissues through transient expression. A GUS activity assay was performed in plant tissues transiently expressing VvGRIP24::GUS or VvUBIL40::GUS. Assays were performed in $200 \mathrm{mg}$ of 110 Ritchter rootstock embryogenic tissue, Cabernet Sauvignon leaves and roots and Thompson seedless berry discs. The same tissues were agroinfiltrated with a 35S::GUS construct as positive controls and non-transformed tissues were included as negative controls. Images are representative of five transient expression assays per tissue for each promoter. Constructions were generated in the PKGWFS7 vector (Karimi et al., 2002). Bar $=1 \mathrm{~mm}$. 
Therefore, we have identified two native grape promoters with expression in different tissues and under several conditions. Both promoters are functional in Arabidopsis and grapevine tissues. However, further analyses are needed in order to define clearly their expression patterns by stable transformation in grapes and for developing their use in different approaches to improve agronomic traits in grapes.

\section{ACKNOWLEDGEMENTS}

This work was supported by the Corfo Innova 07 Genoma 01 Project, FONDECYT 1100709 and the Millennium Nucleus for Plant Functional Genomics (P10-062-F). We are grateful to Dr. Michael Handford (Universidad de Chile) for critically reading the manuscript and assistance in language support.

\section{REFERENCES}

AGASSE A, VIGNAULT C, KAPPEL C, CONDE C, GERÓS H AND DELROT S (2009) Sugar transport and sugar sensing in grape. In Grapevine molecular physiology and biotechnology (Roubelakis-Angelakis, K.A., ed. New York: Springer, pp. 105-139.

BAJAJ S, PUTHIGAE S, TEMPLETON K, BRYANT C, GILL G, LOMBA P, ZHANG H, ALTPETER F AND HANLEY Z (2008) Towards engineering drought tolerance in perennial ryegrass using its own genome. 6 th Canadian plant genomics workshop., Abstract p. 62.

BEYER P, AL-BABILI S, YE X, LUCCA P, SCHAUB P, WELSCH R AND POTRYKUS I (2002) Golden Rice: introducing the beta-carotene biosynthesis pathway into rice endosperm by genetic engineering to defeat vitamin A deficiency. J Nutr, 132, 506S-510S.

BRADFORD KJ, VAN DEYNZE A, GUTTERSON N, PARROTT W AND STRAUSS SH (2005) Regulating transgenic crops sensibly: lessons from plant breeding, biotechnology and genomics. Nat Biotechnol, 23, 439-444.

BROOKES G AND BARFOOT P (2013) Key environmental impacts of global genetically modified (GM) crop use 1996-2011. GM Crops Food, 4.

CALLIS J, RAASCH JA AND VIERSTRA RD (1990) Ubiquitin extension proteins of Arabidopsis thaliana. Structure, localization, and expression of their promoters in transgenic tobacco. J Biol Chem, 265, 12486-12493.

CARBARINO JE, OOSUMI T AND BELKNAP WR (1995) 1solation of a Polyubiquitin Promoter and Its Expression in Transgenic Potato. Plants Plant Physiol, 109, 1371-1378.

CATIC A, SUN ZY, RATNER DM, MISAGHI S, SPOONER E, SAMUELSON J, WAGNER G AND PLOEGH HL (2007) Sequence and structure evolved separately in a ribosomal ubiquitin variant. Embo J, 26, 3474-3483.

CHAWLA R, SHAKYA R AND ROMMENS CM (2012) Tuber-specific silencing of asparagine synthetase-1 reduces the acrylamide-forming potential of potatoes grown in the field without affecting tuber shape and yield. Plant Biotechnol J, 10, 913-924.

CLIVE J (2012) Global Status of Commercialized Biotech/GM Crops: 2012, Ithaca, NY: ISAAA, Brief No. 44.

CUTANADA M, AGEORGES A, GÓMEZ C, VIALET S, TERRIER N, ROMIEU C AND TORREGROSA L (2009) Ectopic expression of VlmybA1 in grapevine activates a narrow set of genes involved in anthocyanin synthesis and transport. Plant Mol Biol, 69, 633-648.

DAVIES C AND ROBINSON SP (2000) Differential screening indicates a dramatic change in mRNA profiles during grape berry ripening. Cloning and characterization of cDNAs encoding putative cell wall and stress response proteins. Plant Physiol, 122, 803-812.

DE VETTEN N, WOLTERS AM, RAEMAKERS K, VAN DER MEER, I, TER STEGE R, HEERES E, HEERES P AND VISSER R (2003) A transformation method for obtaining marker-free plants of a cross-pollinating and vegetatively propagated crop. Nat Biotechnol, 21, 439-442.

DEAN R, VAN KAN JA, PRETORIUS ZA, HAMMOND-KOSACK KE, DI PIETRO A, SPANU PD, RUDD JJ, DICKMAN M, KAHMANN R, ELLIS, J AND FOSTER GD (2012) The Top 10 fungal pathogens in molecular plant pathology. Mol Plant Pathol, 13, 414-430.

DELUC LG, GRIMPLET J, WHEATLEY MD, TILLETT RL, QUILICI DR, OSBORNE C, SCHOOLEY DA, SCHLAUCH KA, CUSHMAN JC AND CRAMER GR (2007) Transcriptomic and metabolite analyses of Cabernet Sauvignon grape berry development. BMC Genomics, 8, 429.
GENETICALLY MODIFIED ORGANISMS (GMO) (2012). Scientific opinion addressing the safety assessment of plant developed through cisgenesis and intragenesis. EFSA J, 10, 2561 (33pp).

ESPINOZA C, VEGA A, MEDINA C, SCHLAUCH K, CRAMER G AND ARCE-JOHNSON P (2007) Gene expression associated with compatible viral diseases in grapevine cultivars. Funct Integr Genomics, 7, 95-110.

ESTRUCH JJ, CAROZZI NB, DESAI N, DUCK NB, WARREN GW.AND KOZIEL MG (1997) Transgenic plants: an emerging approach to pest control. Nat Biotechnol, 15, 137-141.

FILLION L, AGEORGES A, PICAUD S, COUTOS-THEVENOT P, LEMOINE R, ROMIEU C AND DELROT S (1999) Cloning and expression of a hexose transporter gene expressed during the ripening of grape berry. Plant Physiol, 120, 1083-1094.

FUNKE T, HAN H, HEALY-FRIED ML, FISCHER M AND SCHONBRUNN E (2006) Molecular basis for the herbicide resistance of Roundup Ready crops. Proc Natl Acad Sci U S A, 103, 13010-13015.

GADALETA A, GIANCASPRO A, BLECHL AE AND BLANCO A (2008) A transgenic durum wheat line that is free of marker genes and expresses 1DY10. J. Cereal Sci., 48, 439-445.

GADOURY DM, CADLE-DAVIDSON L, WILCOX WF, DRY IB, SEEM RC AND MILGROOM MG (2012) Grapevine powdery mildew (Erysiphe necator): a fascinating system for the study of the biology, ecology and epidemiology of an obligate biotroph. Mol Plant Pathol, 13, 1-16.

GESSLER C, PERTOT I AND PERAZZOLLI M (2011) Plasmopara viticola: a review of knowledge on downy mildew of grapevine and effective disease management. Phytopathologia Mediterranea, 50, 3-44.

HAN KM, DHARMAWARDHANA P, ARIAS R, MA C, BUSOV V AND STRAUSS SH (2011) Gibberellin-associated cisgenes modify growth, stature and wood properties in Populus. Plant Biotechnol J, 9, 162-178.

HAVERKORT AJ, STRUIK PC, VISSER RGF AND JACOBSEN E (2009) Applied Biotechnology to Combat Late Blight in Potato Caused by Phytophthora Infestans. Potato Research, 52, 249-264.

HAYES MA, DAVIES C AND DRY IB (2007) Isolation, functional characterization, and expression analysis of grapevine (Vitis vinifera L.) hexose transporters: differential roles in sink and source tissues. J Exp Bot, 58, 1985-1997.

HOFFMAN NE, KO K, MILKOWSKI D AND PICHERSKY E (1991) Isolation and characterization of tomato cDNA and genomic clones encoding the ubiquitin gene ubi3. Plant Molecular Biology, 17, 1189-1201.

HOLME IB, DIONISIO G, BRINCH-PEDERSEN H, WENDT T, MADSEN, CK, VINCZE E AND HOLM PB (2012) Cisgenic barley with improved phytase activity. Plant Biotechnol J, 10, 237-247.

HOLME IB, WENDT T AND HOLM PB (2013) Intragenesis and cisgenesis as alternatives to transgenic crop development. Plant Biotechnol J, 11, 395-407.

JOSHI SG, SCHAART JG, GROENWOLD R, JACOBSEN E, SCHOUTEN HJ AND KRENS FA (2011) Functional analysis and expression profiling of HcrVf1 and HcrVf2 for development of scab resistant cisgenic and intragenic apples. Plant Mol Biol, 75, 579-591.

KARIMI M, INZE D AND DEPICKER A (2002) GATEWAY vectors for Agrobacterium-mediated plant transformation. Trends Plant Sci, 7, 193-195.

KATHAGE J AND QAIM M. (2012) Economic impacts and impact dynamics of Bt (Bacillus thuringiensis) cotton in India. Proc Natl Acad Sci U S A, 109, 11652-11656.

KAWCHUK LM, ARMSTRONG JD, LYNCH DR AND KNOWLES NR (1999) Potatoes having improved quality characteristics and methods for their production. US patent application. US 5998701.

KOBAYASHI S, ISHIMARU M, HIRAOKA K AND HONDA C (2002) Myb-related genes of the Kyoho grape (Vitis labruscana) regulate anthocyanin biosynthesis. Planta, 215, 924-933.

KRAMER M AND REDENBAUGH K (1994) Commercialization of a tomato with an antisense polygalacturonase gene: The FLAVR SAVRTM. Euphytica, 79, 293-297.

LARRONDE F, KRISA S, DECENDIT A, CHÈZE C, DEFFIEUX, G AND MÉRILLON JM (1998) Regulation of polyphenol production in Vitis vinifera cell suspension cultures by sugars. Plant Cell Reports, 17, 946-950.

LI ZT, KIM, KH, JASINSKI JR, CREECH MR AND GRAY DJ (2012) Largescale characterization of promoters from grapevine (Vitis spp.) using quantitative anthocyanin and GUS assay systems. Plant Science, 196, $132-142$.

LIU P, GOH, CJ, LOH CS AND PUA EC (2002) Differential expression and characterization of three metallothionein-like genes in Cavendish banana (Musa acuminata). Physiol Plant, 114, 241-250.

LU J, SIVAMANI E, LI X AND QU R (2008) Activity of the $5^{\prime}$ regulatory regions of the rice polyubiquitin rubi3 gene in transgenic rice plants as 
analyzed by both GUS and GFP reporter genes. Plant Cell Rep, 27, 15871600.

MANN DG, KING ZR, LIU W, JOYCE BL, PERCIFIELD RJ, HAWKINS JS, LAFAYETTE PR, ARTELT BJ, BURRIS JN, MAZAREI M, BENNETZEN JL, PARROTT WA AND STEWART CN JR (2011) Switchgrass (Panicum virgatum L.) polyubiquitin gene (PvUbi1 and PvUbi2) promoters for use in plant transformation. BMC Biotechnol, 11, 74.

MARUYAMA-NAKASHITA A, NAKAMURA Y, WATANABE-TAKAHASHI, A, INOUE E, YAMAYA T AND TAKAHASHI H (2005) Identification of a novel cis-acting element conferring sulfur deficiency response in Arabidopsis roots. Plant J, 42, 305-314.

NORRIS SR, MEYER SE AND CALLIS J (1993) The intron of Arabidopsis thaliana polyubiquitin genes is conserved in location and is a quantitative determinant of chimeric gene expression. Plant Mol Biol, 21, 895-906.

ORGANISMS E.P.O.G.M. (2012) Scientific opinion addressing the safety assesment of plants developed through cisgenesis and intragenesis.

OWEN MD AND ZELAYA IA (2005) Herbicide-resistant crops and weed resistance to herbicides. Pest Manag Sci, 61, 301-311.

PARK TH, VLEESHOUWERS VGAA, JACOBSEN E, VAN DER VOSSEN E AND VISSE RGF (2009) Molecular breeding for resistance to Phytophthora infestans (Mont.) de Bary in potato (Solanum tuberosum L.): a perspective of cisgenesis. Plant Breeding, 128, 109-117.

PRAY CE, HUANG J, HU R AND ROZELLE S (2002) Five years of Bt cotton in China - the benefits continue. Plant J, 31, 423-430.

PURCHASE I (2005) What determines the acceptability of genetically modified food that can improve human nutrition?. . Toxicology and Applied Pharmacology 207, 19-27.

QUINN JM, BARRACO P, ERIKSSON M AND MERCHANT S (2000) Coordinate copper- and oxygen-responsive Cyc6 and Cpx1 expression in Chlamydomonas is mediated by the same element. J Biol Chem, 275, 6080-6089.

REID KE, OLSSON N, SCHLOSSER J, PENG F AND LUND ST (2006) An optimized grapevine RNA isolation procedure and statistical determination of reference genes for real-time RT-PCR during berry development. BMC Plant Biol, 6, 27.

ROBINSON NJ, TOMMEY AM, KUSKE C AND JACKSON PJ (1993) Plant metallothioneins. Biochem J, 295 ( Pt 1), 1-10.

ROH J, CHOI JY, LI MS, JIN BR AND JE YH. (2007) Bacillus thuringiensis as a specific, safe, and effective tool for insect pest control. J Microbiol Biotechnol, 17, 547-559.

ROMMENS CM, HUMARA JM, YE J, YAN H, RICHAEL C, ZHANG L, PERRY R AND SWORDS K (2004) Crop improvement through modification of the plant's own genome. Plant Physiol, 135, 421-431.

ROMMENS CM, BOUGRI O, YAN H, HUMARA JM, OWEN J, SWORDS K AND YE J (2005) Plant-derived transfer DNAs. Plant Physiol, 139, 13381349.

ROMMENS CM, YE J, RICHAEL C AND SWORDS K (2006) Improving potato storage and processing characteristics through all-native DNA transformation. J Agric Food Chem, 54, 9882-9887.

ROMMENS CM, HARING MA, SWORDS K, DAVIES HV AND BELKNAP WR (2007) The intragenic approach as a new extension to traditional plant breeding. Trends Plant Sci, 12, 397-403.
ROMMENS CM, YAN H, SWORDS K, RICHAEL C AND YE J (2008) Lowacrylamide French fries and potato chips. Plant Biotechnol J, 6, 843-853.

SCHAART JG, KRENS FA, PELGROM KT, MENDES O AND ROUWENDAL GJ (2004) Effective production of marker-free transgenic strawberry plants using inducible site-specific recombination and a bifunctional selectable marker gene. Plant Biotechnol J, 2, 233-240.

SCHOUTEN HJ, KRENS FA AND JACOBSEN E (2006a) Cisgenic plants are similar to traditionally bred plants: international regulations for genetically modified organisms should be altered to exempt cisgenesis. EMBO Rep, 7, 750-753.

SCHOUTEN HJ, KRENS FA AND JACOBSEN E (2006b) Do cisgenic plants warrant less stringent oversight? Nat Biotechnol, 24, 753.

SINGH OV, GHAI S, PAUL D AND JAIN RK (2006) Genetically modified crops: success, safety assessment, and public concern. Appl Microbiol Biotechnol, 71, 598-607.

VANBLAERE T, SZANKOWSKI I, SCHAART J, SCHOUTEN H, FLACHOWSKY H, BROGGINI GA AND GESSLER C (2011) The development of a cisgenic apple plant. J Biotechnol, 154, 304-311.

VEGA A, GUTIÉRREZ RA, PENA-NEIRA A, CRAMER GR AND ARCEJOHNSON P (2011) Compatible GLRaV-3 viral infections affect berry ripening decreasing sugar accumulation and anthocyanin biosynthesis in Vitis vinifera. Plant Mol Biol, 77, 261-274.

VIGNAULT C, VACHAUD M, CAKIR B, GLISSANT D, DEDALDECHAMP F, BUTTNER M, ATANASSOVA R, FLEURAT-LESSARD P, LEMOINE R AND DELROT S (2005) VvHT1 encodes a monosaccharide transporter expressed in the conducting complex of the grape berry phloem. J Exp Bot, 56, 1409-1418.

WALKER A, LEE E. AND ROBINSON S (2006) Two new grape cultivars, bud sports of Cabernet Sauvignon bearing pale-coloured berries, are the result of deletion of two regulatory genes of the berry colour locus. Plant Mol Biol, 62, 623-635.

WALKER AR, LEE E, BOGS J, MCDAVID DA, THOMAS MR AND ROBINSON SP (2007) White grapes arose through the mutation of two similar and adjacent regulatory genes. Plant J, 49, 772-785.

WEEKS JT, YE J AND ROMMENS CM.(2008) Development of an in planta method for transformation of alfalfa (Medicago sativa). Transgenic Res, 17, 587-597.

WILLIAMS LE, LEMOINE R AND SAUER N (2000) Sugar transporters in higher plants--a diversity of roles and complex regulation. Trends Plant Sci, 5, 283-290.

WORMIT A, TRENTMANN O, FEIFER I, LOHR C, TJADEN J, MEYER S, SCHMIDT U, MARTINOIA E AND NEUHAUS HE (2006) Molecular identification and physiological characterization of a novel monosaccharide transporter from Arabidopsis involved in vacuolar sugar transport. Plant Cell, 18, 3476-3490.

XUE T, LI X. ZHU W, WU C, YANG G AND ZHENG C (2009) Cotton metallothionein GhMT3a, a reactive oxygen species scavenger, increased tolerance against abiotic stress in transgenic tobacco and yeast. J Exp Bot, 60, 339-349.

YAMAGUCHI T AND BLUMWALD E (2005) Developing salt-tolerant crop plants: challenges and opportunities. Trends Plant Sci, 10, 615-620.

ZHENG Y, TIAN L, LIU H, PAN Q. ZHAN J. AND HUANG W (2009) Sugars induce anthocyanin accumulation and flavanone 3-hydroxylase expression in grape berries. Plant Growth Regul, 58, 251-260. 
